\title{
Detection of Atrazine and Simazine in Ground Water of Delhi using High Performance Liquid Chromatography with Ultraviolet Detector
}

\author{
MOHD ASLAM ${ }^{1,2}$, MASOOD ALAM ${ }^{2}$ and SUMBUL RAIS ${ }^{2 *}$ \\ ${ }^{1}$ Center of Excellence in Environmental Studies, King Abdulaziz University, Jeddah-21589, Saudi Arabia \\ ${ }^{2}$ Department of Applied Sciences and Humanities, Faculty of Engineering and Technology, \\ Jamia Millia Islamia, New Delhi - 110 025, India.
}

http://dx.doi.org/10.12944/CWE.8.2.21

(Received: July 08, 2013; Accepted: August 01, 2013)

\begin{abstract}
Herbicide usage has increased dramatically during the last two decades coinciding with the change in farming practices and increasingly intensive agriculture. This study thus assesses herbicide occurrence in the ground water of Delhi i.e. Atrazine and Simazine herbicide. Liquid-liquid extraction with dichloromethane and methanol as extracting solvents were used. These extracted herbicides were separated and quantified by High Performance Liquid Chromatography (HPLC) with ultraviolet detector. The excellent results were achieved with spiked recoveries of $96.8 \%$ and $84.6 \%$ for atrazine and simazine respectively. Analysis shows that the concentration of simazine was higher as compared to atrazine. The results obtained were compared with WHO limit of 0.002 $\mathrm{mg} / \mathrm{l}$ and USEPA limit of $0.003 \mathrm{mg} / \mathrm{l}$ for Atrazine and $0.004 \mathrm{mg} / \mathrm{l}$ for Simazine. Highest concentration of atrazine was recorded in the north region of Delhi. Sample from the central Delhi did not reveal contamination from any of the herbicides being monitored. The results indicate that there is need for further work to identify sources and fate of herbicide contaminations. The findings of our investigation contribute to the knowledge of the extent of pollution in the groundwater of Delhi.
\end{abstract}

Key words: Herbicides, Simazine, Atrazine, Groundwater, HPLC

\section{INTRODUCTION}

Herbicides belong to the class of pesticides that are used to control undesirable or noxious plant growth, generally weeds, in the crop production. These are also used in non-crop areas, where it is necessary to limit the plant growth ${ }^{1}$. They are, therefore, also called weed killers. Herbicide usage has increased dramatically during the last two decades coinciding with the change in farming practices and increasingly intensive agriculture ${ }^{2}$. Herbicides show a wide range of beneficial effects such as improving the plant health, maintaining agro-ecosystems, food supply and other economical advantages ${ }^{3}$.

After application of herbicide on target weeds, the active ingredient is gradually lost as a result of breakdown, evaporation and leaching. The herbicide residue is the amount that remains on the field after application and usage ${ }^{4}$. As some herbicides have long residual activity and they persist in the environment for long time. Others have low residual activity and disappear from the environment and produce low residual concentrations ${ }^{5}$. The identification and quantification of environmental pollutants are important in determining the extent of exposure to these compounds and in evaluating the hazard to humans and wildlife. Environmental pollution by pesticide residues is a major environmental concern due to their extensive use in agriculture and public health programs ${ }^{6}$. The extensive use of herbicides in agriculture and the high persistence of many of them have required rigorous control of environmental contamination, especially of ground water and drinking water sources ${ }^{7}$. Pesticide residues above the tolerance limits (MRL) are a cause of great concern globally as well as nationally. The intensive application of herbicides has resulted 
in the contamination of the atmosphere, ground and waste waters, agricultural products such as wheat, corn, fruits, vegetables, etc. and biological systems ${ }^{8}$.

Pesticides monitoring of water is also possible with rapid and simple methods that use less sophisticated instruments which still provide reliable identification of analytes ${ }^{9}$. Thermo labile or non-volatile herbicides can be determined only by liquid chromatographic methods such as thin-layer chromatography (TLC) and high-performance liquid chromatography (HPLC). Reversed-phase HPLC is widely used in analyses of pesticides with high polarity, low volatility and thermal instability. Because of its higher sensitivity HPLC has been widely applied in the measurement of herbicide residues.

Where an MS detector is not available an ultraviolet (UV) or photodiode array detector (PDA) is frequently employed ${ }^{10,11}$. Liquid-liquid extraction is frequently used for the isolation of pesticides from water samples and dichloromethane is the most common solvent because it is capable of extracting compounds having a wide range of polarities while its volatility makes sample concentration easy ${ }^{12}$.

The main chemical classes of herbicides include, triazine derivatives containing three heterocyclic nitrogen atoms in the ring structure (atrazine, simazine, etc. as shown in Fig. 1)

Atrazine (6-chloro- $N^{2}$-ethyl- $N^{4}$-isopropyl1,3,5-triazine-2,4-diamine) is one of the most used pesticides worldwide ${ }^{13,14}$ for pre and post emergence weed control amongst crops of corn, wheat, barley and sorghum. A large amount of applied atrazine and its degradation products remain in the soil even after 16 months, which suggest its potential to contaminate groundwater ${ }^{15}$. It can also be said that because of their relatively high water solubility symmetric triazine herbicides are agrochemical agents with a potentially high risk of leaching into surface and ground waters ${ }^{16,17}$. The Half- life of Atrazine was determined to be approximately 223 days $^{18}$. According to USEPA the Potential Health Effects from long-term exposure above the MCL (unless specified as short-term) by atrazine is on Cardiovascular system and is also responsible for reproductive problems.
Simazine (6-chloro-N,N'-diethy1$(1,3,5)$ triazine-2,4-diamine) is one of the most popular photosynthesis-inhibiting herbicides. It is used in many countries to kill broad-leaved weeds and also to control vegetation and algae in farm ponds, fish hatcheries, swimming pools, fountains, ornamental fish ponds \& water-recirculating cooling towers. Although EU directives have banned the use of simazine on non-cropped land, its use is still permitted on cropped land and in ornamental water (ponds, aquariums) ${ }^{19}$. It affects the blood on LongTerm Exposure ${ }^{20}$.

\section{MATERIALS AND METHODS}

Groundwater samples were collected from Delhi. The extraction procedure was undertaken within $72 \mathrm{~h}$. The organic solvents, acetonitirile, methanol, methylenechloride and water, used were HPLC grade and were purchased from E. Merck. Pesticide standards were obtained from Accustandards with a purity of 95$99 \%$. All solvents were filtered through Millipore membrane filters (polysulfone membrane with $0.45 \mu \mathrm{m}$ pore size) before using as mobile phase. The samples were filtered using Millipore syringe filters (polysulfone membrane with $0.45 \mu \mathrm{m}$ pore size) before injecting in the column.

Anhydrous sodium sulfate for the residue analysis, 60-100 mesh was maintained at $300^{\circ} \mathrm{C}$ overnight and stored in desiccators till used Individual standard stock solutions of Atrazine and Simazine containing $1 \mathrm{mg} / \mathrm{ml}$ in methanol were prepared and stored at $4^{\circ} \mathrm{C}$. After the extraction and cleanup procedure, samples were stored in glass container at the recommended temperature.

Herbicides were extracted thrice from the groundwater sample $(1000 \mathrm{ml})$ using liquid-liquid partitioning into dichloromethane $(50 \mathrm{ml})$. After extraction, the supernatant was evaporated to dryness and redissolved in $5 \mathrm{ml}$ of Methanol.

All samples were cleaned up by passing through anhydrous sodium sulfate (pretreated at $300^{\circ} \mathrm{C}$ ) and eluted with $50 \mathrm{ml}$ methanol. The organic phase thus obtained was evaporated to dryness in a rotary vaccum evaporator completely at a temperature of $40-45^{\circ} \mathrm{C}$ and then dissolved in methanol for HPLC analysis. 
Perkin Elmer High Performance Liquid Chromatography (isocratic) having Ultraviolet detector, integrated with Totalchrom software. Stainless steel analytical column Spheri-10 Reverse Phase C18 of $250 \times 4.6 \mathrm{~mm}$ i.d., partical size-10um was used. The samples were injected manually through a Rheodyne injector. Working conditions for HPLC were as follows: The Eluent solvent was acetonitrile/water $(60: 40, \mathrm{v} / \mathrm{v})$ at Flow

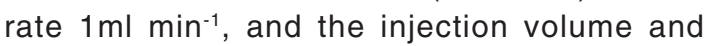
detection wavelength were $20 \mu \mathrm{l}$ and $235 \mathrm{~nm}$, respectively.

The identification of target pesticides were accomplished on the basis of the retention times of the analytes.

\section{RESULTS AND DISCUSSION}

Contamination of surface, ground and drinking water by the studied herbicides has been reported in many countries ${ }^{1,20,21,22,23}$. The compounds are separated with good resolution and sharp peak by gradient HPLC using a simple mobile phase containing acetonitrile:water $(60: 40, \mathrm{v} / \mathrm{v})$. The extraction procedure employed resulted recoveries of $96.8 \%$ and $84.6 \%$ for atrazine and simazine respectively. Several mobile phase flow rates $(0.5$ - $2 \mathrm{ml} / \mathrm{min}$ ) were evaluated. The best separation was achieved using a flow rate of $1.0 \mathrm{ml} / \mathrm{min}$. Fig. $2 a \& 2 b$ shows the chromatogram referring to HPLC analysis of atrazine and simazine herbicides respectively. Fig. 3 is the chromatogram obtained by analyzing analytical standard where as spiked water chromatogram is shown in Fig. 4. Fig. 5 represents the chromatograms for the water samples from the region of interest (Delhi). Analysis of the results on table 2 shows that the concentration of simazine was higher as compared to atrazine. Maximum Contaminant Level Goal (MCLG), the level of a contaminant in drinking water below which there is no known or expected risk to health, allow for a margin of safety and are non-enforceable public health goals. Maximum Contaminant Level (MCL) is however the highest level of a contaminant that is allowed in drinking water. The MCLG and MCL values for Atrazine and Simazine are 0.003 and $0.004 \mathrm{mg} / /$ respectively ${ }^{24}$. In the present study, highest concentration of atrazine was recorded in the north region of Delhi. Sample from the central Delhi did not reveal contamination from any of the herbicides being monitored. The atrazine was detected in $45 \%$ water samples analysed where as $35 \%$ samples exceeded the WHO and USEPA limit. Simazine was detected in $85 \%$ analysed samples with $50 \%$ samples exceeding the limit according to USEPA and 55\% exceeding the WHO limit (Table 2). The total mean concentrations of atrazine and simazine ranged from 0.00072 to $0.0173 \mathrm{mg} / \mathrm{l}$ and 0.00091 to $0.04097 \mathrm{mg} / \mathrm{l}$ respectively.

The findings of our investigation contribute to the knowledge of the extent of pollution in the groundwater of Delhi. The total mean concentration of atrazine ranged from 0.00072 to $0.0173 \mathrm{mg} / \mathrm{l}$ where as 0.00091 to $0.04097 \mathrm{mg} / \mathrm{l}$ are recorded as the mean concentration of simazine. It is important to monitor the pesticides and see whether they have caused contamination in the hydrological system

Table 1:Physicochemical properties of atrazine and simazine ${ }^{a}$

\begin{tabular}{lll}
\hline Property & Atrazine Value & Simazine Value \\
\hline Mol. Wt. & 215.7 & 201.72 \\
Melting point & $175-177{ }^{\circ} \mathrm{C}$ & $25-227{ }^{\circ} \mathrm{C}$ \\
Density & $1.187 \mathrm{~g} / \mathrm{cm}^{3}$ at $20^{\circ} \mathrm{C}$ & $1.302 \mathrm{~g} / \mathrm{cm}^{3}$ at $20^{\circ} \mathrm{C}$ \\
Water solubility & $33 \mathrm{mg} / \mathrm{l} \mathrm{at} 20^{\circ} \mathrm{C}$ & $6.2 \mathrm{mg} / \mathrm{l}$ at $20^{\circ} \mathrm{C}$ \\
pKa (Acid dissociation constant) & 1.70 (base) & $1.62($ base) \\
Log $K_{\text {ow }}$ (Log octanol-water partition & & 2.1 \\
coefficient) & 2.5 & $8.1 \times 10^{-4} \mathrm{~Pa}$ at $20^{\circ} \mathrm{C}$ \\
Vapour pressure & $40 \times 10^{\prime 6} \mathrm{~Pa}$ at $20^{\circ} \mathrm{C}$ & \\
\hline
\end{tabular}

${ }^{a}$ data obtained from Tran et al., 2007 
Table 2. Herbicide concentrations in the water samples of Delhi with statistical data

\begin{tabular}{|c|c|c|}
\hline Sample No. & Atrazine (ppm) & Simazine (ppm) \\
\hline Sample 1 & ND & 0.004326 \\
\hline Sample 2 & ND & 0.022492 \\
\hline Sample 3 & 0.0098 & 0.000912 \\
\hline Sample 4 & 0.017316 & 0.0098 \\
\hline Sample 5 & 0.00098 & 0.004008 \\
\hline Sample 6 & 0.00072 & 0.00154 \\
\hline Sample 7 & 0.00715 & 0.0014 \\
\hline Sample 8 & ND & ND \\
\hline Sample 9 & 0.010651 & 0.0106 \\
\hline Sample 10 & ND & ND \\
\hline Sample 11 & 0.009315 & 0.006255 \\
\hline Sample 12 & ND & ND \\
\hline Sample 13 & 0.00462 & 0.010714 \\
\hline Sample 14 & ND & 0.022415 \\
\hline Sample 15 & ND & 0.040979 \\
\hline Sample 16 & ND & 0.001722 \\
\hline Sample 17 & 0.00711 & 0.0017 \\
\hline Sample 18 & ND & 0.013587 \\
\hline Sample 19 & ND & 0.015409 \\
\hline Sample 20 & ND & 0.009714 \\
\hline Average & 0.0033831 & 0.00887865 \\
\hline Maximum & 0.017316 & 0.040979 \\
\hline Minimum & 0 & 0 \\
\hline Std Deviation & 0.00508707 & 0.010350463 \\
\hline Average Deviation & 0.00422803 & 0.007580215 \\
\hline Variance population & 2.45844E-05 & 0.000101775 \\
\hline Median & 0 & 0.0052905 \\
\hline Mode & 0 & 0 \\
\hline USEPA Limit & 0.003 ppm & 0.004 ppm \\
\hline WHO Limit & 0.002 ppm & 0.002 ppm \\
\hline$\%$ of samples exceeding USEPA limit & 35 & 50 \\
\hline$\%$ of samples exceeding WHO limit & 35 & 55 \\
\hline
\end{tabular}

ND : Not Detected<smiles>CCNc1nc(Cl)nc(NC(C)C)n1</smiles>

Atrazine<smiles>CCNc1nc(Cl)nc(NCC)n1</smiles>

Simazine

Fig. 1: Structure of Atrazine and Simazine 


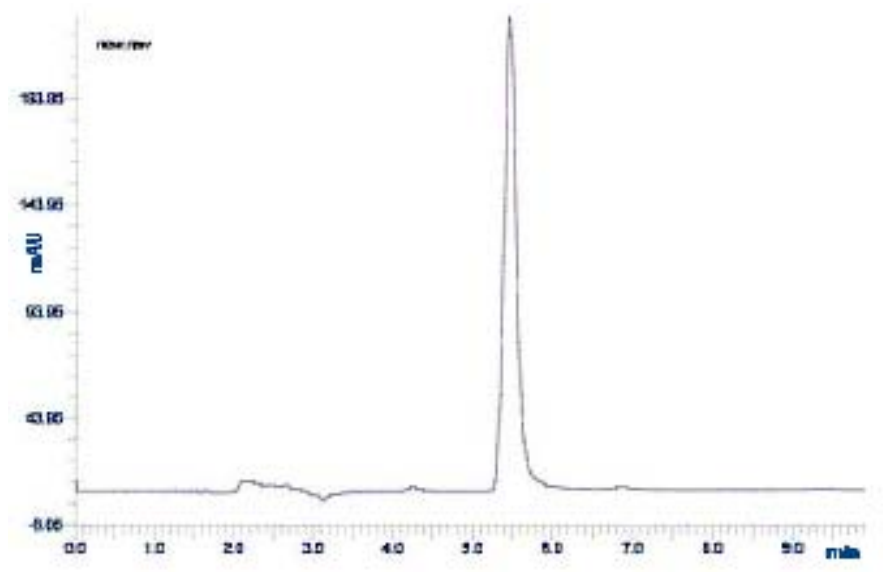

Fig. 2(a): HPLC Chromatogram obtained by analyzing Atrazine Standard.

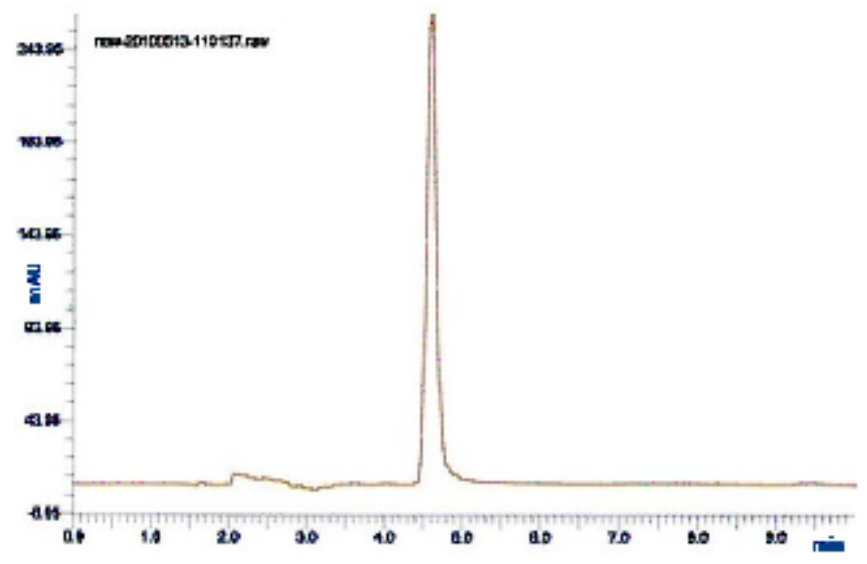

Fig. 2(b): HPLC Chromatogram obtained by analyzing Simazine Standard

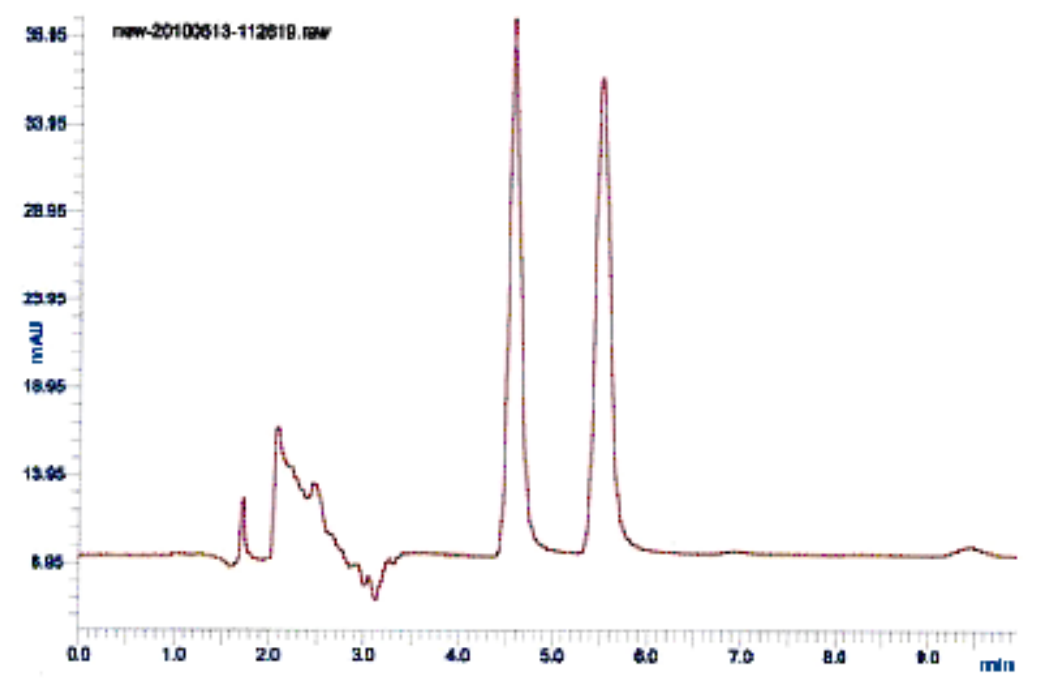

Fig. 3: HPLC Chromatogram obtained by analyzing Standard Simazine \& Atrazine 


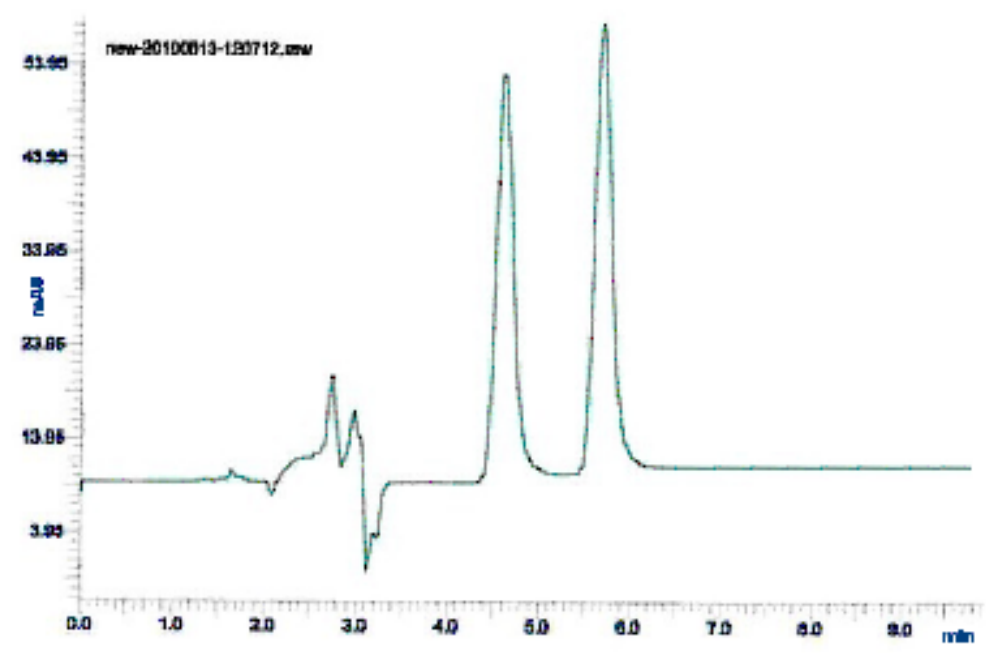

Fig. 4: HPLC Chromatogram obtained by analyzing Spiked water Sample

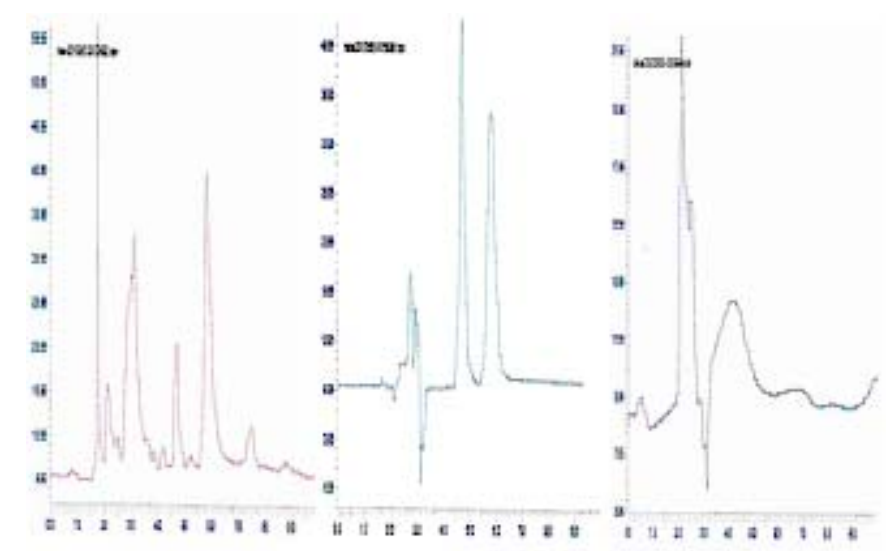

Fig. 5: HPLC Chromatogram a) Showing Atrazine concentration more than Simazine. b) Showing Simazine concentration more than Atrazine. c) Showing no peak in the interested area

this will also help to take necessary actions in minimising the chances of further deterioration and prevent exposure of large population of Delhi from health hazards due to chemical contamination.

\section{REFERENCES}

1. Guzzella L, Pozzoni F and Giuliano G., Herbicide contamination of suficial groundwater in Northern Italy, Environ Poll, 142: 344-353 (2006).

2. Readman J. W, Albanis T. A, Barcelo D, Galassis S, Tronczynski J and Gabrielides G.P., Herbicide contamination of Medeterranean Estuarine waters: Results from a MED POL pilot survey, Marine Poll. Bulletin, 26(11): 613-619 (1993).

3. Cserhati T, Forgacs E, Deyl Z, Miksik I and Eckhardt A., Chromatographic determination of herbicide residues in various matrices. Biomed. Chromatogr, 18: 350-359 (2004).

4. Afful S., Thin layer chromatographic studies 
on depletion of some herbicides in two soil ecosystems, M.Phil. Thesis, Department of Chemistry, University of Ghana, Legon, (2002).

5. Walker A, Herbicides and the Soil, Proc EWRS Symposium, 240-250 (1973).

6. Barlas N, Cok I and Akbulut N., The concentration levels of organochlorine pesticides in water and sediments samples in Uluabat lake, Turkey, Environ. Monit. Assess, 118: 383-391 (2006).

7. Lanchote V. L, Bonato P. S, Cerdeira A. L, Santos N. A. G, Carvalho D and Gomes M. A., HPLC Screening and GC-MS confirmation of triazine herbicides residues in drinkingwater from sugar cane area in Brazil, Water, Air, and Soil Pol., 118: 329337 (2000).

8. Johnen B. G., Herbicides and food quality a misfit? In Proceedings of Brighton Conference, Weeds, Vol. 3. British Crop Protection Council, UK, 875-882 (1999).

9. Balinova A., Solid-phase extraction followed by high-performance liquid chromatographic analysis for monitoring herbicides in drinking water, J Chrom, 643: 203-207(1993a).

10. Balinova A., Ion-pairing mechanism in the solid-phase extraction and reversed-phase high-performance liquid chromatographic determination of acidic herbicides in water, J Chrom, 728: 319-324 (1993b).

11. Pichon V, Coumes C. D, Chen L, Guenu S and Hennion M. C., Simple removal of humic and fulvic acid interferences using polymeric sorbents for the simultaneous solid-phase extraction of polar acidic, neutral and basic pesticides, J. Chromatogr A, 737: 25-33 (1996).

12. Parrilla $P$ and Martinez Vidal J. L., Determination residues in water using LLE or SPE and HPLC/DAD detection, Analytical Letters, 30: 1719-1738 (1997).

13. Berg M, Muller S. R and Schwarzenbach R. P., Simultaneous Determination of Triazines Including Atrazine and Their Major Metabolites Hydroxyatrazine, Desethylatrazine, and Deisopropylatrazine in Natural Waters, Anal. Chem, 67: 18601865 (1995) .
14. Vitali P, Venturini E, Bonora C, Calori R and Raffaelli R., Determination of triazines and dinitroanilines in waters by highperformance liquid chromatography after solid-phase extraction, J. Chromatogr A, 660: 219-222 (1994).

15. Kyoung S. Ro and Kyu H. Chung., Pesticides and herbicides, Water Environ Res, 66(4): 432-433 (1994).

16. Masse L, Patni N. K, Jui P.Y and Clegg B. S., Groundwater Quality under Conventional and No Tillage: II. Atrazine, Deethylatrazine, and Metolachlor, J. Environ. Qual., 27: 877883 (1998).

17. Cogger C. G, Bristow P. R, Stark J. D and Getzin L. W., Transport and Persistence of Pesticides in Alluvial Soils: I. Simazine, J. Environ Qual, 27: 543-550 (1998).

18. Chung K, Starrett $S$, Chung $Y$ \& Kyoung $S$ Ro, Pesticides and Herbicides, Water Environ Res, 70(4): 693-697 (1998).

19. DEFRA, ACP Annual Report. Pesticides Safety Directorate (PSD), London, UK. (1993).

20. Drevenkar V, Fingler S, Mendas G, Stipicevic $S$ and Vasilic Z., Levels of Atrazine and Simazine in waters in the rural and urban areas of north-west Croatia, Intern. J. Environ Anal Chem, 84: 207-216 (2004).

21. Queiroz S. C. N, Lazou K, Sandra P and Jardium I.C.S.F., Determination of pesticides in water by liquid chromatography(Electrospray ionization)- mass spectrometry (LC-ESI-MS), Pesticides: R. Ecotoxicol, e Melo Ambiente, Curitiba., 14: 53-60 (2004).

22. Tran A. T. K, Hyne R. V and Doble P., Determination of commonly used polar herbicides in agricultural drainage waters in Australia by HPLC, Chemosphere, 67: 944-953 (2007).

23. Zhou Q, Pang L, Xie G, Xiao J and Bai H., Determination of Atrazine and Simazine in Environmental water samples by dispersive LLME with HPLC, Analytical Sci, 25: 73-76 (2009).

24. Drinking Water Standards and Health Advisories, United State Environmental Protection Agency. (2006). 